\title{
ELEMENTOS CONSTITUTIVOS DO ESTADO E POVOS INDÍGENAS ISOLADOS EM SITUAÇÃO TRANSFRONTEIRIÇA: UM EXAME CRÍTICO À LUZ DOS CONCEITOS DE “HOMO SACER” E “CAMPO” DE AGAMBEN
}

RESUMO: O presente artigo se preocupa com a vulnerabilidade dos povos indígenas em situação transfronteiriça. Há incipiente amparo normativo aos mesmos. É complexo, o enquadramento ao conceito de Estado. Entretanto, a figura estatal, avocou deveres com relação a todos aqueles que habitam seus territórios. É possível protegê-los de toda vulnerabilidade em que hodiernamente se encontram, sem comprometer a soberania e a integridade territorial dos sujeitos estatais? O índio personifica a figura do homo sacer e as aldeias, tornam-se o local onde se realiza a mais absoluta "conditio inhumana", o campo. Foi adotada pesquisa bibliográfica.

PALAVRAS-CHAVES: Povos Indígenas Isolados. Situação Transfronteiriça. Estado. Vida Nua. Homo Sacer.

\section{CONSTITUTIVE ELEMENTS OF THE STATE AND INDIGENOUS PEOPLES ISOLATED IN A CROSS-BORDER SITUATION: A CRITICAL EXAMINATION IN THE LIGHT OF THE CONCEPTS OF "HOMO SACER" AND "CAMPO" OF AGAMBEN}

ABSTRACT: This article is concerned with the vulnerability of indigenous peoples in crossborder situations. There is incipient normative protection to them. It is complex, the framing of the concept of State. Meanwhile, the state figure, has imposed duties on all those who inhabit their territories. Is it possible to protect them from all vulnerability in which they are today, without compromising the sovereignty and territorial integrity of the state subjects? The Indian personifies the figure of homo sacer and the villages, they become the place where the most absolute "inhuman conditio", the field. Bibliographic research was adopted.

KEYWORDS: Isolated Native Peoples. Transboundary Situation. State. Bare Life. Homo Sacer.

\footnotetext{
${ }^{1}$ Mestranda em Direito pela Universidade Federal de Sergipe - UFS. Bolsista da CAPES. Bacharela em Direito pela Universidade Estadual de Alagoas- UNEAL. E-mail: thayseedith@hotmail.com

${ }^{2}$ Mestranda em Direito pela Universidade Federal de Sergipe - UFS. Bacharela em Direito, graduada pela Universidade Federal de Sergipe - UFS (2005). Atualmente é titular do cartório de RCPN da Comarca de Candeias/BA.
} 


\section{CONSIDERAÇÕES INICIAIS}

Comunidades indígenas e tribais ocupam uma posição de elevada vulnerabilidade no universo jurídico. Entretanto, a disparidade entre o conjunto normativo de proteção a esses povos (plano interno e internacional dos direitos humanos) e a realidade ao qual vivenciam, não encerra o diagnóstico acerca da fragilidade a que estão sujeitos.

A categoria de povos indígenas em isolamento voluntário que habitam zonas fronteiriças de Estado-Nação é atormentada por fatores que agravam a situação de insegurança ao qual, povos originários já contactados enfrentam. Pois, essa vulnerabilidade específica carece de maior amparo jurídico, sendo a recente Declaração Americana Sobre Os Direitos dos Povos Indígenas (2016) o único documento normativo que expressamente reserva em seu texto, (art. 26) duas curtas passagens sobre povos tribais em isolamento sem, contudo, tecer apontamentos aos que estão nas zonas de limite territorial dos Estados.

Há constatação de agrupamentos humanos que não mantêm contato, com a sociedade maior (CASTILLO, 2002), e que estão ausentes de vínculo jurídico, nacionalidade, com a figura estatal. Assim, questiona-se a famosa trindade POVO - TERRITÓRIO- GOVERNO que marca intensamente o pensamento da ciência política moderna e aproveita-se ao deslinde do Direito Internacional.

O montante de pessoas naturais, vinculados a um ente estatal por meio da nacionalidade ou da cidadania configura “o elemento humano do Estado” (PORTELA, 2017, p. 109). No entanto, os povos na situação examinada no presente artigo são seminômades (CASTILLO, 2002), transitam livremente entre territórios de países distintos, tornando impossível precisar seus locais de nascimento, relativamente ao critério do jus soli para aquisição de nacionalidade e estão sem contato permanente com a sociedade moderna, o que lhes inviabiliza conhecer acerca dos procedimentos e regras pertinentes a naturalização.

Afirmar existir elo jurídico entre índios bravos fronteiriços e um Estado em específico, dentro dos padrões convencionais de aquisição de nacionalidade, nata ou naturalizada, é tarefa praticamente impossível. Porém, não se pode negar que os mesmos estão incluídos no contingente quantitativo dos Estados, a população. Visto que, esta "independe de qualquer laço jurídico de sujeição ao poder estatal” (PORTELA, 2017, p. 169).

O espaço geográfico/físico dentro do qual o Estado exerce sua jurisdição denominase, território. Âmbito em que se desenvolve o atributo de maior relevo do ente estatal, a soberania. Esta última, possui duas noções: a de soberania interna e internacional (MAZZUOLLI, 2011). 


\section{ELEMENTOS CONSTITUTIVOS DO ESTADO E POVOS INDÍGENAS ISOLADOS EM SITUAÇÃO TRANSFRONTEIRIÇA: UM EXAME CRÍTICO À LUZ DOS CONCEITOS DE "HOMO SACER” E “CAMPO” DE AGAMBEN}

O aspecto interno guarda singular conflito com a existência de povos tribais em isolamento voluntário na divisa dos territórios de países, pois refere-se a superioridade da figura estatal frente a todos os centros de poder que atuam dentro do Estado, inclusive em detrimento da autodeterminação desses núcleos humanos originários.

Entretanto, os países possuem (art.9) o dever de proteger todos os habitantes que se encontrem dentro dos limites do respectivo território nacional (CONVENÇÃO DE MONTEVIDEU, 1933) e (art. 6) todo indivíduo tem o direito de ser em todos os lugares reconhecido como pessoa perante a lei (DECLARAÇÃO UNIVERSAL DOS DIREITOS DO HOMEM E DO CIDADÃO, 1948).

Embora seja complexo e discutível o enquadramento na tríade pertinente ao conceito de Estado, dos povos não contactados que habitam nas regiões de limite territorial entre entes nacionais é certo, que o destacado sujeito do Direito Internacional possui diversos deveres inerentes a proteção de todas as pessoas que transitam em seu espaço geográfico.

O Direito a autodeterminação desses povos está disciplinado em importantes dispositivos normativos internacionais e resumidamente consiste na garantia (artigos 3 e 4) de determinarem livremente sua condição política e buscarem de forma autônoma as condições de desenvolvimento econômico, cultural e social, além do respeito ao autogoverno (DECLARAÇÃO DAS NAÇÕES UNIDAS SOBRE DIREITOS DOS POVOS INDÍGENAS, 2007). Compreende também, (art. 21) o direito a manterem e desenvolverem suas próprias instituições de decisões (DECLARAÇÃO AMERICANA SOBRE OS DIREITOS DOS POVOS INDIGENAS, 2016).

A autonomia dos índios sem contato com a sociedade majoritária guarda íntima relação com estratégias de sobrevivência física e cultural. Estão em extrema vulnerabilidade, pois sofrem hodiernamente ameaças de atores que buscam explorar os recursos naturais existentes em seus territórios (ALTO COMISSARIADO DAS NAÇÕES UNIDAS PARA OS DIREITOS HUAMANOS, 2012).

O tema ganha relevância a partir da necessidade de refletir a dinâmica da situação desses povos indígenas na sociedade contemporânea. Nesse contexto, o pensamento de Giorgio Agamben (1995) revela a existência de um espaço onde é possível aproximar o tratamento do índio oculto com a existência de uma vida nua e a sua imagem particular, o homo sacer. A vida desses povos permeia o jogo das lutas políticas, por isso “a sacralidade é uma linha de fuga ainda presente na política contemporânea, que como tal, desloca-se em direção a zonas cada 
vez mais vastas e obscuras, até coincidir com a própria vida biológica” (AGAMBEN, 1995. p. 113).

A impunidade costuma predominar diante das agressões a estes povos e seus ecossistemas. Toda essa violência que muitas vezes se traduz num extermínio étnico, permanece insancionável. Qualquer um pode cometer assassinato a esses grupos sem que tal fato constitua homicídio e estará, livre de condenação penal. O óbito do índio personifica a figura do homo sacer as aldeias, tornam-se o local onde se realiza a mais absoluta "conditio inhumana” que tenha existido na terra, o campo (AGAMBEN, 1995).

As responsabilidades assumidas pelos Estados em importantes instrumentos de proteção internacional dos direitos humanos vislumbram efetivar a garantia a autodeterminação desses povos. Assim, é possível protegê-los de toda vulnerabilidade em que hodiernamente encontram-se, sem comprometer a soberania e a integridade territorial dos sujeitos estatais?

\section{METODOLOGIA}

O estudo em exame debruça-se sobre povos tribais em isolamento voluntário que habitam faixas fronteiriças entre países distintos haja vista, toda pesquisa científica carecer de um objeto de estudo "reconhecível e definido de tal maneira que seja reconhecível igualmente pelos outros” (ECO, 1977, p. 21).

Averiguar a situação de vulnerabilidades desses grupos originários a luz dos elementos centrais da Teoria Geral do Estado consiste no objetivo geral deste trabalho. Quanto as metas específicas, destacam-se: a) investigar se povos não contactados que transitam livremente entre limites nacionais personificam, ante todo grau de ameaça a que estão sujeitos, os conceitos de homo sacer e campo de Giorgio Agamben (1995) e b) apurar o deslinde do aparente conflito entre o direito a autonomia dessas populações e a noção de soberania do Estado, manifestada em seu espaço físico.

Toda a literatura utilizada será direcionada ao teste da hipótese, que a autodeterminação de povos isolados que se movem nas regiões de divisa geográfica entre países, derroga a soberania estatal controvertendo a trindade povo, território e governo. Contudo, essa resposta será testada e fundamentada, sendo um aspecto extremamente importante da hipótese a possibilidade de sua rejeição (RICHARDSON et al., 1985).

O meio, método, utilizado para testar a indagação apresentada no tópico anterior será a pesquisa bibliográfica, combinado com a aplicação da análise doutrinária, jurisprudencial e 


\section{ELEMENTOS CONSTITUTIVOS DO ESTADO E POVOS INDÍGENAS ISOLADOS EM SITUAÇÃO TRANSFRONTEIRIÇA: UM EXAME CRÍTICO À LUZ DOS CONCEITOS DE “HOMO SACER” E “CAMPO” DE AGAMBEN}

normativa como técnicas de pesquisa. No entanto, todo caminho científico necessita da observância de determinadas regras e procedimentos, por isso a metodologia aplicada será a qualitativa, pois se pretende compreender o fenômeno (objeto) investigado de forma adequada, superando a análise meramente estatística sobre o tema.

Os estudos que empregam uma metodologia qualitativa podem descrever a complexidade de determinado problema, analisar a interação de certas variáveis, compreender e classificar processos dinâmicos vividos por grupos sociais, contribuir no processo de mudança de determinado grupo e possibilitar, em maior nível de profundidade, o entendimento das particularidades do comportamento dos indivíduos (RICHARDSON et al., 1985, p. 80).

\section{POVOS INDÍGENAS ISOLADOS}

Em 2012 no âmbito de diretrizes elaboradas pela ONU sobre o tema foi apresentada uma estimativa de quantos grupos indígenas vivem em isolamento na Amazônia e na Região do Gran Chaco. O resultado supõe existirem 200 povos bravos, representando uma população aproximada de 10.000 (dez mil) pessoas.

Existe um prognóstico de que Bolívia, Equador, Brasil, Colômbia, Paraguai, Peru e Venezuela possuem dentro de seus limites territoriais povos tribais que nunca estabeleceram comunicação permanente com a sociedade ocidental. Brasil, Peru e Bolívia, respectivamente, são os Estados que possuem o maior número de referenciais ${ }^{3}$ que apontam a existência dos mesmos (CIDH, 2013).

Essas gentes têm habitado o continente americano desde muito antes da fixação de fronteiras nacionais. É verdade que inúmeros foram assassinados ante o processo de colonização estabelecido na América, outros tantos, foram assimilados por missões de catequese que tentavam tornar o silvícola dócil ao domínio escravocrata, e, pouquíssimos sobreviveram a essas etapas históricas sendo recentemente, ameaçados por interesses econômicos daqueles que desejam explorar a variedade de recursos naturais presentes em seus territórios - madeiras, combustíveis fósseis, minerais, recursos hídricos e outros (CASTILLO, 2002).

\footnotetext{
${ }^{3}$ Para a FUNAI, o termo Referência é toda e qualquer informação acerca da presença de índios isolados e de recente contato em uma determinada região do território nacional, devidamente cadastrada no banco de dados da Coordenação Geral de índios Isolados e de Recente Contato da FUNAI - CGIIRC/FUNAI (VAZ, 2013, p. 19).
} 
Pertinente a noção sobre essas populações, a CIDH (2013) informa que se tratam de povos ou segmentos de povos que normalmente coíbem qualquer contato com a sociedade majoritária. Essa inibição comunicativa é uma opção realizada pelos grupos não contactados, uma decisão voluntária. Tribos que já estabeleceram certo grau de diálogo com não indígenas também podem regressar ao retiro anterior, rompendo relações com a comunidade nacional.

A compreensão apresentada supera a expectativa alimentada pelo exotismo, de ainda existirem massas humanas que desconhecem por completo a sociedade dita "civilizada; visualizando-os como grupos que têm permanecido estanques no tempo (CASTILLO, 2002). O conhecimento acerca do tema que parte de um viés de salvação perante as formas primitivas de organização desses povos é assimilacionista e inviabiliza entender a complexidade da questão. O isolamento, inúmeras vezes, é resultado de um primeiro contato extremamente negativo, marcado pela violência.

Nesse ínterim, a CIDH (2013) destaca um ponto interessante para o termo “opção voluntária” visto que, nem sempre essa condição é livre ou opcional mais antes, um recurso de estratégia adotado pelos silvícolas para sobrevivência física e cultural do grupo. A expressão é resultado de pressões praticadas pela sociedade envolvente sobre suas terras ancestrais.

Os povos indígenas em situação de contato inicial são aqueles que vêm mantendo uma relação intermitente ou esporádica com a população não nativa. Não obstante, o vocábulo “inicial” não se refira exclusivamente ao aspecto temporal. Ao revés, guarda ínfima conexão com o pouco grau de interação com a sociedade majoritária. Anteriormente foram povos invisíveis, mas por algum motivo, opcional ou não, passaram a se relacionar com a população envolvente não indígena. Devido a isso, ainda não conhecem plenamente os padrões e códigos de interação da sociedade ocidental (CIDH, 2013).

Algumas denominações são comumente utilizadas para se referir aos povos tribais em isolamento, sendo as mais usuais: maskos; calatos; índios bravos; não contactados; isolados; povos livres; povos invisíveis; ocultos; selvagens; etc (CASTILLO, 2002).

Existem comunidades originárias que vivem na região amazônica e transitam livremente em ambos os lados da fronteira internacional. Visto que, as zonas de perambulação desses povos são anteriores a fixação de limites territoriais dos Estados Nacionais. Exemplificando, numa região bastante remota e pouco habitada na fronteira Peru-Brasil, compreendendo o território dos departamentos peruanos de Ucayali e Madre de Dios e o extremo ocidente do estado brasileiro do Acre, habitam cerca de 4 (quatro) grupos indígenas isolados, provavelmente da mesma família linguística, os Pano (CASTILLO, 2002). 


\section{ELEMENTOS CONSTITUTIVOS DO ESTADO E POVOS INDÍGENAS ISOLADOS EM SITUAÇÃO TRANSFRONTEIRIÇA: UM EXAME CRÍTICO À LUZ DOS CONCEITOS DE "HOMO SACER” E “CAMPO” DE AGAMBEN}

Tradicionalmente, esses povos invisíveis em situação transfronteiriça são seminômades e suas aldeias estão localizadas as margens de importantes rios tanto no lado brasileiro como, no peruano. Outro elemento de destaque acerca do modo de vidas desses povos, é que suas rotas tradicionais de deslocamento, definidas a alguns séculos atrás e mantidas até os dias atuais, são orientadas pelas estações do ano. No período chuvoso costumam permanecer em terras peruanas e no verão, buscam refúgio nas partes baixas dos rios localizadas no Brasil (CASTILLO, 2002). Também há indícios da presença de povos ocultos na zona Bolívia-Brasil, além de outras zonas limites no território tupiniquim (CIDH, 2013).

Importante destacar, que as pressões socioeconômicas ao qual hodiernamente são vítimas, podem estar sendo estimuladas pelos Estados ao disponibilizarem ilimitadamente concessões para que empresas privadas e públicas explorem os domínios da selva amazônica em prol de uma política desenvolvimentista (VAZ, 2013). Esse tipo de ação força mudanças nas rotas ancestralmente desenvolvidas por povos isolados, ao passo que populações que viviam permanentemente no território de um determinado país passam a buscar as zonas fronteiriças como refúgio das ameaças que vieram a sofrer (CASTILLO, 2002).

\subsection{Direito a autodeterminação e princípio do não contato}

A opção em permanecerem em isolamento é uma das premissas mais destacadas para preservação dessas populações indígenas, pois “se elimina o contato não desejado, se elimina a maioria das ameaças e se garante o respeito aos direitos de tais povos” (CIDH, 2013, p. 16). A livre determinação é corolário do princípio do não contato e dentre as suas razões podem ser apontadas a proteção a diversidade cultural, uma vez que o desaparecimento de índios invisíveis representa uma perda para toda a humanidade.

Para povos em não contato com a sociedade majoritária, o direito sobre seus territórios e recursos naturais possui estreita conexão com a autodeterminação. Convém pontuar uma preocupação da CIDH (2013) quanto ao isolamento nas áreas ancestrais, este deve ser compreendido como uma estratégia escolhida livremente pelos índios e não como resultado de exclusão e marginalização social.

A profunda relação que mantêm com o meio ambiente lhes possibilita viver de maneira autossuficiente por várias gerações. A autonomia significa o respeito as suas opções de 
sobrevivência física e cultural segundo, usos e costumes próprios. O retiro deve ser compreendido como um modo de exercitar o direito a autodeterminação (CIDH, 2013).

Apesar de serem titulares de direitos humanos, a condição de isolamento inviabiliza a capacidade de pleitearem seus direitos tornando-os extremamente vulneráveis frente a outros grupos. É por isso que o direito a autodeterminação dos mesmos deve ser interpretado de maneira especial comparando-se com povos indígenas já contactados. Contudo, não deve ser entendido como algo que possibilita uma faixa isenta de aplicação legal por parte dos poderes estatais. A autonomia não exprime tendências separatistas ou pretensões autárquicas (ALTO COMISSARIADO DAS NAÇÕES UNIDAS PARA OS DIREITOS HUMANOS, 2012).

O mencionado direito encontra-se positivado em esparsos dispositivos do direito internacional: a) artigo 1 dos Pactos Internacionais de Direito Civil e Político e Sociais, Econômicos e Culturais; b) artigos 3, 4 e 5 da Declaração das Nações Unidas sobre Direitos dos Povos Indígenas e c) artigos 3, 14, 17 e 21 da Declaração Americana sobre os Direitos dos Povos Indígenas.

\section{POVOS TRANSFRONTEIRIÇOS A LUZ DOS ELEMENTOS CONSTITUTIVOS DO ESTADO}

É cediço que o Estado goza de importante papel no Direito Internacional, haja vista participar ativamente da elaboração da maioria das normas de Direito das Gentes, sobretudo tratados e colaborar com a formação de organizações internacionais (MAZZUOLLI, 2011). A figura estatal apresenta como elementos constitutivos: a) o governo soberano, que expressa a não subordinação a qualquer outro núcleo de poder; b) uma comunidade humana denominada, povo e c) um território.

O significado de Nação não se confunde com a noção de Estado, uma vez que a primeira guarda conexão com proximidades históricas, culturais, étnicas, religiosas, etc e não reúne todas as noções elementares do ente estatal. O sujeito originário do Direito Internacional (Estado) pode abrigar diversas nações, inclusive as indígenas (MAZZUOLLI, 2011).

A Convenção de Montevidéu (1933) apresenta importantes aspectos sobre os direitos e deveres do Estado. Informa (art. 1) os fundamentos essenciais que o habilita a ser sujeito internacional; sustenta (art. 3) não estar subordinado a outros limites além do exercício dos direitos de outros entes, consoante o direito das gentes e afirma (art.9) que a jurisdição do 


\section{ELEMENTOS CONSTITUTIVOS DO ESTADO E POVOS INDÍGENAS ISOLADOS EM SITUAÇÃO TRANSFRONTEIRIÇA: UM EXAME CRÍTICO À LUZ DOS CONCEITOS DE “HOMO SACER” E “CAMPO” DE AGAMBEN}

Estado se aplica, dentro do seu respectivo espaço físico, a todos os habitantes (nacionais ou estrangeiros).

Como foi dito alhures, o território corresponde ao espaço geográfico onde o poder soberano se desenvolve; o povo difere da população e refere-se a todas as pessoas que estão jungidas a figura estatal por uma espécie de laço jurídico, nacionalidade e cidadania e o governo, versa sobre o poder político, o mecanismo de supremacia sobre pessoas e bens que suplanta outros centros de poder, tais como as comunidades indígenas.

A abordagem acerca dos primados constitutivos do Estado numa perspectiva conflituosa com a autonomia dos povos invisíveis que circulam nas faixas de fronteiras nacionais enseja uma discussão a partir do pensamento de Hannah Arendt (1951), especialmente devido ao drama dos displaced people.

Destituídos de cidadania, tornam-se o refugo da terra, pois não comportam os mesmos sentidos jurídicos que a sociedade majoritária atribui as organizações política e social e, ocorrem imprecisões aos vinculá-los juridicamente, nacionalidade, através do ius solis. Como precisar seus locais de nascimento? Desse modo, não usufruem dos benefícios da legalidade e não se valem dos direitos humanos que são titulares, visto que o isolamento lhes impossibilita de conhecer esses códigos normativos (ARENDT, 1951).

A existência de pessoas sem documentos para atestar a identidade - sans papiers possibilita a execução de práticas à margem da lei e recrudesce o poder das polícias (LAFER, 2015). A desnacionalização incapacitou e ainda, incapacita os entes estatais de proteger efetivamente os direitos humanos, visto que "as minorias [...] não dispunham de governos que os representassem e protegessem e, por isso, eram forçadas a viver ou sob leis de exceção [...], ou sob condições de absoluta ausência da lei” (ARENDT, 1951, p. 371).

Nesse ínterim, as minorias indígenas invisíveis são reduzidas a mera existência física, a uma vida nua, postas para a parte externa da jurisdição humana sem superar a parcela divina, configurando uma dupla exceção. Estão sujeitas a um poder de morte e expostas ao completo abandono (AGAMBEN, 1995). E os direitos humanos convertem-se em "idealismo fútil ou tonta e leviana hipocrisia” (ARENDT, 1951, p.372).

A situação dos povos mencionados é extremamente complexa, porque apesar de habitarem um corpo político que assumiu inúmeros deveres com todos os que permanecem/transitam dentro do seu espaço físico, necessita de proteção adicional, sob a forma de tratados internacionais. A realidade aponta que os Estados não estão aptos a protegerem a 
autonomia desses povos por meio de mecanismos próprios, no entanto a medida que o direito internacional busca salvaguardar esses sujeitos, a figura estatal se opõe sob o pretexto de ameaça aos seus elementos constitutivos. E adicionalmente, convém registrar a incipiente proteção internacional acerca dos povos em situação transfronteiriça.

A autonomia de grupos indígenas que vivem nas fronteiras nacionais corresponde metaforicamente a uma espécie de nacionalidade de fato não reconhecida pelos entes estatais, pois como dizia Arendt (1949) a nação majoritária (não índios) conquistou o Estado e transformou todos seus instrumentos de lei, em mecanismos a serviço unicamente da sociedade não indígena que almeja vê esses grupos assimilados e divorciados de sua identidade étnica para explorarem com liberdade os riquíssimos recursos presentes em suas terras.

\section{A INSACRIFICABILIDADE E MATABILIDADE DO INDÍGENA FRONTEIRIÇO NO CONTEXTO INTERNACIONAL}

Ao apresentar os meios de aquisição do domínio terrestre dos Estados, Valério Mazzuoli aponta a ocupação como uma apropriação permanente por parte de um Estado em relação a um território que julga ser sem dono. Mesmo que o espaço seja ocupado por tribos ou povos desprovidos de organização política ou sem sistematização suficiente para reclamar ocupação anterior, a apropriação de terras pelas grandes potências determinou a destruição do corpo social que vivia mansa e pacificamente nessas terras (MAZZUOLI, 2011). Como exemplo prático dessa concepção internacionalista de ocupação, a situação dos indígenas no Brasil.

A imagem do índio banido de seu território, tornado escravo e reduzido a uma vida sem valor, despojada de tradições e crenças, reflete a dimensão de uma vida nua analisada por Giorgio Agamben. A imagem do homo sacer relaciona-se a uma condição de banimento, a qual a vida insacrificável é, todavia, matável, tonando-se vida sacra (AGAMBEN, 1995).

O filósofo italiano traz a figura enigmática do direito romano arcaico "homo sacer"aquele que foi retirado do mundo dos vivos, expulso da sociedade- e passa a pertencer aos Deuses (consagrado a Júpiter), por essa condição não poderia, ser sacrificável (no sentido ritualístico ou religioso). De outra parte, por ainda continuar vivo, porém, excluído da sociedade (porque a lei não o contempla), fica sujeito à matabilidade pela comunidade, sem que haja qualquer sanção pela sua morte. Em resumo, a noção etnográfica de tabu, ou seja, a ambivalência do sacro.

Revista de Sociologia, Antropologia e Cultura Jurídica | e-ISSN: 2526-0251 | Salvador | v. 4 | n. 1 | p. 22 - 40 | Jan/Jun. 2018 


\section{ELEMENTOS CONSTITUTIVOS DO ESTADO E POVOS INDÍGENAS ISOLADOS EM SITUAÇÃO TRANSFRONTEIRIÇA: UM EXAME CRÍTICO À LUZ DOS CONCEITOS DE "HOMO SACER” E “CAMPO” DE AGAMBEN}

A insacrificabilidade e a matabilidade insancionável do índio está ligada à falta de reconhecimento de seu valor político ou de qualquer estratégia que pudesse representar sua incorporação ao ordenamento, na visão dos conquistadores (soberanos), tornando passível de ser exterminado pela mera conveniência. A morte, portanto, não tinha qualquer significado ou importância, recaindo num corpo desprovido de direitos, sendo, portanto, autorizada.

O curso da história atesta o genocídio de grupos originários a partir de decisões políticas, em outros termos, esses povos correspondem ao registro mais intenso na memória brasileira da politização da vida, da biopolítica. Comparato (2013) registra a aquiescência da coroa portuguesa com as situações de massacre dos índios, citando a carta de padre Antônio Vieira a D. Afonso VI, rei de Portugal, em 1657, na qual se verifica o massacre de índios que totalizou, em quarenta anos, a morte de mais de dois milhões de índios e mais de quinhentas povoações como grandes cidades, sem que nenhum castigo fosse dado quanto a esses fatos.

Essa imagem, projetada mais atualmente, da existência de um homem que pode ser morto impunemente, subsiste no estado moderno e permite perceber que a condição de vida nua, apresentada por Giorgio Agamben, persiste em comunidades indígenas, especialmente, as que vivem em regiões fronteiriças, onde é flagrante a situação de vulnerabilidade. Estão expostos às violações de toda sorte, despojados de direitos políticos instituídos pelo Estado, com os quais não reconhecem, uma vez que suas identidades civis dentro do território que se situam enfrentam dificuldades de serem determinadas. Deste modo, as populações transfronteiriças não são vistas na dimensão de cidadão, mas como mero corpo humano, mera vida nua.

Seguem excluídos por diversos fatores: pelo interesse de segurança do ente estatal; por processos institucionais, como é o caso da demora na demarcação de terras indígenas no Brasil, na qual os interesses de grandes proprietários costumam sobrepor-se aos dos silvícolas e à lei, sendo flagrante a fragilidade dos dispositivos de proteção e de autodeterminação.

Na linha do pensamento de Agamben, a análise da teoria política contemporânea apresentada implica em observar o processo de proteção por meio de declarações de direitos. Para ele, o sujeito político implícito nos documentos da democracia moderna é a vida nua, ou seja, vida despojada de todo valor político. Um sintagma do paradigma inclusão-exclusiva, “a norma se aplica à exceção desaplicando-se, retirando-se desta” (AGAMBEN, 2007, p. 25).

Transpondo a análise para o caso dos povos indígenas transfronteiriços, enquanto sujeitos do Direito Internacional, verifica-se que a invocação encontrada na base das 
declarações de direitos considera preocupações acerca de uma vida abandonada, exposta à formas de discriminação, de modo a prever reparação de danos em relação à propriedade cultural, intelectual, religiosa, ou espiritual (Declaração da ONU sobre direitos dos povos indígenas, 2007); direito à autodeterminação, incluído autogoverno nas questões relacionadas a assuntos internos e locais; direito à nacionalidade, sendo colocados como patrimônio comum da humanidade (Declaração das Nações Unidas sobre os Direitos dos Povos Indígenas, 2007).

A preocupação dos textos internacionais demonstra a implicação da vida natural dessas populações nos mecanismos e espaços de poder político, "não o homem livre, com suas prerrogativas e os seus estatutos, e nem ao menos simplesmente homo, mas corpus é o novo sujeito da política” (AGAMBEN, 2007, p. 129). Descortina-se aqui a condição do índio como corpo absolutamente matável, que é inserido no campo político do Ocidente, cuja vida passa a fazer parte dos assuntos políticos, não com toda a sua identidade e diversidade cultural, bem como autodeterminação, mas como condição de sujeição ao poder de morte.

O instrumento que trata de povos tribais em isolamento - Declaração Americana Sobre os Direitos dos Povos Indígenas, aprovada pela OEA em 2016, num processo que levou 17 anos - prevê o direito de transitar, permanecer, desenvolver relações em cooperação e atividades espirituais, culturais, políticas, econômicas e sociais entre seus membros e com outros povos. Em que pese a proteção internacional contida no texto, as comunidades indígenas, localizadas em zonas de divisões geográficas entre Estados, preferem permanecer voluntariamente no estado de isolamento, indicando os estigmas deixados pela experiência histórica.

As causas desse isolamento estão ligadas ao período de ocupação colonial e decorrem de fugas para terras mais altas, acima de cachoeiras, com dificuldade de acesso, normalmente inabitáveis. Porém, tais fatos geradores perduram e agravam-se nas faixas de divisa, em face da priorização geopolítica das fronteiras pelos países, como questão de soberania e, de defesa e segurança nacional.

Cite-se como exemplo no Brasil, o impasse entre comunidades indígenas e as Forças Armadas Brasileiras, na demarcação das Terras Indígenas Yanomami (homologada em 1992), com a promulgação no ano de 2002 do Decreto 4.412, que permitiu a liberdade de trânsito e a autonomia para instalação de infraestrutura e projetos do Exército, mesmo em terras indígenas demarcadas.

\section{AS RESERVAS INDÍGENAS ISOLADAS E FRONTEIRIÇAS COMO NÓMOS BIOPOLÍTICO - CAMPO}




\section{ELEMENTOS CONSTITUTIVOS DO ESTADO E POVOS INDÍGENAS ISOLADOS EM SITUAÇÃO TRANSFRONTEIRIÇA: UM EXAME CRÍTICO À LUZ DOS CONCEITOS DE “HOMO SACER” E “CAMPO” DE AGAMBEN}

A formação de reservas indígenas no continente americano, durante o Século XVII, desenvolveu-se por meio de um processo de segregação que não proporcionou uma efetiva integração dos indígenas no corpo social e político da comunidade maior. O próprio termo “silvícola” denota sentido de diferenciação dentro da sociedade e não contempla o significado, que dela faz parte.

O antropólogo guarani-kaiowá Tonico Benites, pesquisador do povo Ava Kaiowá, em entrevista ao Instituto Humanistas Unisinos, no ano de 2012, pontua que as reservas indígenas são espécies de confinamento. Relata que antes da demarcação de terras indígenas, os povos viviam de modo autônomo, saudável e não passavam fome e nem miséria. Todavia, registra que os povos guaranis e kaiowá ao serem desvinculados do seu espaço originário, perderam também o referencial de tradições culturais, posto que foram obrigados a se deslocarem para uma “pequena área cercada e vigiada, como se fosse um chiqueiro humano”.

Tais espaços em que estão inseridas as comunidades indígenas sequer pertencem mais a elas, passaram a incorporar a soberania interna, como é o caso do Brasil, cujas terras pertencem à União. Disso se extrai que a ordem jurídico-política desenvolveu técnicas para se apropriar da vida humana indígena, transformando-a em vida nua, legitimando assim sua soberania.

Nesta circunscrição geográfica residual, resultado das maiores barbáries contra o povo indígena, humilhado, aterrorizado e retraído, ceifado de sua consciência cultural e personalidade, o índio isolado é excluído do contexto político e social que outrora lhe pertencia, e passa a subsistir não mais como membro ativo, mas sujeito passivo e destituído de importância, posto que considerado sub-humano e primitivo. Confinado num espaço geográfico em que o direito está suspenso, a vida dos indígenas se tornou objeto de políticas indigenistas com foco na demarcação de terras.

Aproximando-se da produção intelectual de Agamben esta circunstância tangência a figura do estado de exceção, visto que a exceptio torna-se a única regra válida para essas populações, apresentando-se sob a forma da legalidade aquilo que não pode assumir tal forma, “uma teoria do estado de exceção é, então, condição preliminar para se definir a relação que liga e, ao mesmo tempo, abandona o vivente ao direito” (AGAMBEN, 2007, p. 12).

Castor Roriz, filósofo espanhol, em artigo publicado no ano de 2011, enxerga o espaço denominado reserva indígena, como um embrião jurídico da estrutura de “campo”, apresentada 
na obra de Giorgio Agamben, pois o Estado de Direito, mesmo sendo portador da proclamação e proteção dos direitos naturais de todos os cidadãos cria as reservas indígenas como espaços em que não vigoram os direitos de cidadania, nem se aplicam a constituição do Estado.

De fato, o direito interno permitiu estabelecer limites ao exercício de autodeterminação dos povos indígenas no que concerne ao direito à terra e aos territórios, e ao acesso dos recursos naturais nelas existentes, quando arrebatou para si a decisão quanto à demarcação de terras indígenas, criando teorias próprias para identificar o que pertence ou não aos povos originários. O destino das terras ancestrais passou a pertencer ao ente soberano, o qual logrou definir a porção territorial que caberá aos índios, com reflexos em suas atividades produtivas, bem-estar, reprodução física e cultura.

Nessa zona indistinta entre fato e direito, na qual são definidas as prioridades da sociedade majoritária e o destino dos índios, onde não é possível discernir o lícito e o ilícito, uma vez que a lei não vigora -pois suspensa-e denominada por Giorgio Agamben como “campo”, estabelece-se no seu interior um novo nómos biopolítico.

Nesse contexto contemporâneo, no qual os direitos internacionais baseados no princípio da igualdade e no de não-discriminação - expressos nos Pactos de Direitos Humanos de 1966 - são meramente formais, reproduções simbólicas e indiferentes, é perceptível o agigantamento da estrutura política soberana, que excepciona esses dispositivos legais da ordem internacional, para suspender os direitos nele fixados, excluindo dessa forma a incidência desses direitos aos povos indígenas, mas incluindo sob seu poder de deliberação acerca de seu modo de viver ou não viver.

A reserva isolada forma uma exceção jurídica, na qual o que vale é a governabilidade quanto aos corpos que formam a comunidade indígena, visto não haver efetividade das normas protetivas. Nesse sentido, a reserva transmuta-se em campo, tratado por Giorgio Agamben como a representação interna do Estado de exceção e como "paradigma biopolítico" da sociedade moderna (AGAMBEN, 2007, p. 187).

No campo, a vontade soberana (de quem tem o poder de decidir) substitui a norma, a qual fica suspensa, para definir qual vida humana merece ou não ser vivida. Essa dinâmica é vista nos processos de demarcação indígena em regiões transfronteiriças, nos quais são ignorados os direitos à autodeterminação - o que para seu exercício exige a apropriação de terras e recursos -a fim de dar lugar à decisão política do Estado soberano que delimitará o espaço geográfico. 


\section{ELEMENTOS CONSTITUTIVOS DO ESTADO E POVOS INDÍGENAS ISOLADOS EM SITUAÇÃO TRANSFRONTEIRIÇA: UM EXAME CRÍTICO À LUZ DOS CONCEITOS DE "HOMO SACER” E “CAMPO” DE AGAMBEN}

As aldeias isoladas qualificadas aqui como “campo”, deixam transparecer a relação de bando (relação política originária), pois na interação existente entre os Estados soberanos e a vida nua dos índios que vivem em retiro voluntário, sujeitos à morte e toda espécie de violência, ocorre a insignificação de seus direitos, haja vista aquiescência estatal às investidas dos atores econômicos, ansiosos em controlar suas terras e recursos. Verifica-se, pois, uma cisão do conceito de povo, cujas acepções direcionadas à população indígena transfronteiriça, esvaziamse à medida que lhes falta vínculo nacional.

A inefetividade de direitos consagrados e inalienáveis, mesmo aqueles previstos internamente num Estado, ou resultado da adesão a Tratados e Convenções Internacionais, no âmbito do espaço comunitário dos indígenas (a aldeia) - campo-, reflete que o domínio do soberano é quem vai decidir acerca da continuidade da vida indígena, desnuda, controlada e subjugada, e seu direito de ir e vir, de constituir ou não, o que merece ou não ser valorizado.

Persiste, assim, a existência insacrificável do índio combinada a sua matabilidade insacionável e consequentemente, a implicação de sua vida humana nos mecanismos de poder que estão direcionados aos interesses do soberano, sobretudo aqueles concernentes às disputas de terras e divisões e ocupação dos espaços fronteiriços, somado a não extensão de direitos inerentes ao cidadão, o que o constitui em homo sacer.

O estado inflexível de disputa em reservas fronteiriças e a constante exposição da vida indígena à morte, situação característica de diversas aldeias confinadas em limites geográficos de vários Estados, coloca à lume a condição de exclusão e, ao mesmo tempo, inclusão desses povos no sistema político moderno, ou seja, ao passo em que estão desprovidos de qualquer proteção (exclusão) em virtude da não incidência da norma, estão incluídos no campo pela força irradiadora de decisões políticas (inclusão).

Decerto, a falta de identidade civil das comunidades que não mantém contato com a sociedade majoritária, facilita o desencadeamento de processos de não pertencimento ao elemento povo; deslocando ainda mais os povos indígenas aos campos de isolamento, onde tudo é possível, a partir da vontade soberana, visto ser esta quem define o que é digno ou não, o que permanece ou não, o que vive ou morre.

Tais índios são pessoas que estão "retidas” no espaço geográfico sem identificação com o povo do estado em que estão localizados, não havendo constituição do vínculo nacionalidade-cidadania e, portanto, não representam sujeitos jurídicos (cidadãos), mas mera 
existência humana, simples seres descartáveis. Essa lógica autoriza uma profunda simbiose entre política e vida fisiológica, vista no estágio atual também em relação aos índios.

Nos processos demarcatórios e de controle estatal de faixa de fronteira, há intensa participação da prática de polícia vigilante (No Brasil, consistente na atuação do Exército, Polícia Federal, Ibama), sendo possível visualizar a suspenção de artigos das Declarações de direitos dos povos indígenas - tais como o relativo ao direito à terra, território e recursos, bem como de possuir, utilizar, desenvolver e controlar as terras que possuem em razão da propriedade tradicional ou de ocupação ou de utilização - com a proclamação de um estado de exceção, no qual são reduzidos todos esses direitos à vontade soberana.

Observa-se, ainda, que nas reservas indígenas localizadas em fronteira, a situação permanente em que vivem a população originária é de um constante estado de exceção, o qual não está mais justificado numa situação externa e transitória, mas confunde-se com a própria norma vigorante. É aqui que se vislumbra a inteireza do campo, “num espaço que se abre quando o estado de exceção começa a tornar-se a regra” (ABAMBEN, 2007, p. 175).

Da situação apresentada, vislumbra-se, claramente, o rompimento da estrutura tradicional do Estado-nação, definida por três elementos: território, governo soberano e povo. A estrutura passa a incorporar um quarto elemento, qual seja, a inscrição da via nua no interior do campo. Compete à decisão política determinar o que está dentro e fora, a partir da inclusão dessa conditio inhumana, identificável nos povos indígenas.

\section{CONSIDERAÇÕES FINAIS}

A discussão suscitada no presente trabalho é apenas uma amostra das possibilidades sobre o tema e não pretende ser exaustiva, porém já identifica a situação de singular vulnerabilidade em que o indígena, que ocupa zonas de limite territorial dos Estados, encontrase, posto que não é identificado liame jurídico que o torne um nacional- cidadão. O status de povos ocultos também interroga a tradicional estrutura da teoria geral dos Estados.

Territorialmente, ocupam áreas muito antes da definição dos limites espaciais dos entes estatais e não se submetem a autoridade política da sociedade majoritária, pois possuem autonomia e autogoverno específicos. Convém destacar que a autodeterminação desses grupos deve ser respeitada e, para tanto, é imprescindível a elaboração de acordos bilaterais e/ou multilaterais entre os países. 


\section{ELEMENTOS CONSTITUTIVOS DO ESTADO E POVOS INDÍGENAS ISOLADOS EM SITUAÇÃO TRANSFRONTEIRIÇA: UM EXAME CRÍTICO À LUZ DOS CONCEITOS DE "HOMO SACER” E “CAMPO” DE AGAMBEN}

O reconhecimento desse direito denota uma subversão da linguagem política, haja vista ser indispensável o reconhecimento a diversidade cultural e o respeito a escolha dessas comunidades de viverem isoladas. A autonomia torna-se uma categoria de direito direcionada a um público restrito, povos tradicionais, que inverte a noção inclusão-exclusão. Dado que exclui a sociedade majoritária dos espaços de autossuficiência indígena para incluir o índio bravo no mesmo patamar jurídico dos nacionais. Assim, descaracteriza-se a imagem do silvícola como homo sacer e se desconstrói a aldeia como espaço paradigmático da vida nua; como campo.

A partir da reflexão acerca da política moderna, introduzida por Giorgio Agamben, é possível identificar que os espaços geográficos ocupados por povos indígenas em faixa de fronteira nos territórios dos Estados, constituem-se como “campos”, nos quais a vida dos índios é identificada como uma vida nua. Uma vez que se encontra alijada às intempéries da violência, despida de valores e importância social, passam a serem visualizadas como mera vida biológica submetida à decisão política do soberano.

A figura do índio expulso e retido, enquanto homo sacer, transparece na exclusão histórica e duradoura de suas tradições e formas próprias de organização, em detrimento das escolhas realizadas pelo soberano para a sociedade maior. Revela a vulnerabilidade de um ser passível de ser morto, sem que tal morte seja sancionável.

A análise proposta permite compreender que os direitos à autodeterminação desses povos, consagrados nos documentos internacionais, estão em estado de suspensão, e, portanto, estado de exceção, em prol dos interesses manifestados pelo soberano, colocando o indígena em posição de submissão frente à política atual, entendida como um biopoder regulamentador, na medida em que se apodera cada vez mais da vida nua.

A identificação desse fenômeno contemporâneo proporciona um descortinamento dos aspectos que constituem, a estrutura jurídicopolítica do Estado e faz reconhecer a situação de vulnerabilidade e ineficácia de direitos inscritos aos povos indígenas, em risco constante, pois inseridos num campo, que serve ao desenvolvimento da biopolítica. 


\section{REFERÊNCIAS}

AGAMBEN, Giorgio. Homo Sacer: o poder soberano e a vida nua I. 2.ed.Belo Horizonte: UFMG, 2007.

.Estado de Exceção. 2.ed. São Paulo: Bomtempo, 2007.

ALTO COMISSARIADO DAS NAÇÕES UNIDAS PARA OS DIREITOS HUMANOS. Directrices de Protección para Los Pueblos Indígenas en Aislamiento y en Contacto Inicial de La Región Amazónica, el Gran Chaco y la Región Oriental de Paraguay. Fevereiro de 2012.

ARENDT, Hannah. Origens do Totalitarismo. São Paulo: Companhia das Letras, 2012.

ASSEMBLEIA GERAL DA ORGANIZAÇÃO DOS ESTADOS AMERICANOS. Declaração Universal dos Direitos Humanos. 10 de dezembro de 1948.

ASSEMBLEIA GERAL DA ORGANIZAÇÃO DOS ESTADOS AMERICANOS. Declaración Americana sobre losderechos de losPueblos Indígenas. 7 de junho de 2016. OEA.SER/PAG. Doc. 5537/16.

ASSEMBLEIA GERAL DAS NAÇÕES UNIDAS. Declaração das Nações Unidas Sobre o Direito dos Povos Indígenas. Março de 2008.

BENITES, Tonico. Reservas indígenas são “confinamentos”. Entrevista especial concedida ao Instituto Humanitas Unisinos, Disponível em:

http://www.ihu.unisinos.br/entrevistas/515278-reservas-indigenas-sao-confinamentosentrevista-especial-com-tonico-benites. Acesso em: 15 de julho de 2017.

CASTILLO, Beatriz Huertas. Los Pueblos Indígenas em Aislamiento: Su lucha por La sobrevivência y La libertad. Lima: IWGIA, 2002.

COMISSÃO INTERAMERICANA DE DIREITOS HUMANOS. Pueblos Indígenas em Aislamiento Voluntario y Contacto Incialem las Americas: Recomendaciones para El pleno respeto a sus derechos. 30 de dezembro de 2013. OEA.SER.L/VIII.Doc. 47/13.

COMPARATO, Fábio Konder. A Afirmação Histórica dos Direitos Humanos. 8. Ed. São Paulo: Editora Saraiva, 2013.

ECO, Umberto. Como se faz uma tese. 14.ed. São Paulo: Perspectiva S.A., 1998.

FERREIRA, Elaine Fritas Fernandes. Resistência ao Não Reconhecimento das Diferenças Culturais entre Índios e "Brancos": A Violência contra s Povos Indígenas agravadas pelo Descaso e Omissão do Estado no Caso Raposa Serra do Sol. In: Conpedi. Anais eletrônicos. Florianópolis - SC, 2015. Disponível em: https://www.conpedi.org.br/publicacoes/66fsl345/iy7q98vn/43SVC59wV1k932bC.pdf. Acesso em: 15 de julho de 2017.

LAFER, Celso. Direitos Humanos: um percurso no direito do século XXI. São Paulo: Atlas, 2015.

Revista de Sociologia, Antropologia e Cultura Jurídica| e-ISSN: 2526-0251 | Salvador | v. 4 | n. 1 | p. 22 - 40 | Jan/Jun. 2018 


\section{ELEMENTOS CONSTITUTIVOS DO ESTADO E POVOS INDÍGENAS ISOLADOS EM SITUAÇÃO TRANSFRONTEIRIÇA: UM EXAME CRÍTICO À LUZ DOS CONCEITOS DE "HOMO SACER" E “CAMPO” DE AGAMBEN}

MAZZUOLLI, Valerio de Oliveira. Curso de Direito Internacional Público. 5 ed. rev. atual. e ampl. São Paulo: Revista dos Tribunais, 2011.

PORTELA, Paulo Henrique Gonçalves. Direito Internacional Público e Privado: incluindo noções de direitos humanos e direito comunitário. 9.ed. Salvador: JusPODIVM, 2017.

RICHARDSON, Roberto Jarry. Pesquisa Social: Métodos e Técnicas. Colaboração de José Augusto de Souza Peres et al. 3. ed. São Paulo: Atlas, 1999.

RUIZ, Castor. Homo sacer. O poder soberano e a vida nua, artigo publicado na IHU OnLine número 371, de 29-08-2011.

SILVEIRA, R. D. ; FURBINO, R. E. . O Estado de Exceção e o Homo Sacer: um enfoque jurídico sociológico sobre a importância do processo a partir da obra Memórias do Cárcere de Graciliano Ramos. In: XIX Encontro do Conpedi. Anais eletrônicos. Fortaleza, 2010.

Disponível em:

file://C:/Users/SEVEN/Downloads/a277e1bbcf32bfc3d9bf84e473c90740\%20(1).pdf. Acesso em: 10 de junho de 2017.

SIMONI, Mariana Yokoya. Reconhecimento dos direitos dos povos indígenas sob a perspectiva internacional e a brasileira. Disponível em http://www.ibri-rbpi.org/?p=12317. Acesso 15 de julho de 2017.

UNIÃO PANAMERICANA. Convenção sobre direitos e deveres dos Estados e sobre asilo político. 26 de dezembro de 1937.

VAZ, Antenor. Povos Indígenas Isolados e de Recente Contato no Brasil: políticas, direitos e problemáticas. Brasília, 2013. 